\title{
OBSERVATIONS ON SWARM EMIGRATIONS AND DRAGGING BEHAVIOR BY SOCIAL WASPS (HYMENOPTERA: VESPIDAE)*
}

\author{
By Ruth Chadab and Carl W. Rettenmeyer \\ Biological Sciences Group, University of Connecticut \\ Storrs, Connecticut 06268, U.S.A.
}

Naumann (1975) reported the first evidence that several species of social wasps (Vespidae: Polybiini) use chemical trails to direct swarms to a new nest site. His observations were based on absconding swarms following army-ant raids. Those observations were corroborated by Jeanne (1975, 1980), and most recently by Forsyth (1978) and us. Incidental to investigating raids by army ants on social wasps, we observed that the movement of absconding wasp swarms did not always conform to the trail-following behavior as it has been described. In this report the typical emigrations of absconding swarms will be summarized followed by our observations on two unusual swarm movements and related dragging behavior.

Prior to the movement of a wasp swarm to a new site, some wasps run a few millimeters to centimeters on vegetation dragging their gasters in a zig-zag motion which deposits a chemical produced in Richards' gland (Naumann 1975, Jeanne 1980). Such dragging runs occur first on prominent vegetation near the swarm site and then in various directions from the swarm. Eventually dragging activity consolidates along a path to the new nest site. The behavior of subsequent wasps visiting the dragging sites differs: their gasters do not touch the substrate or move back and forth but they antennate the dragging sites. Those wasps use the chemical traces for orientation and are called "followers."

At the swarm site some workers returning to the swarm behave differently than do regular foragers. They run excitedly through, among, or over clusters of calm wasps. Since increased activity and flight follow, such behavior is considered important for stimulating the wasps to emigrate and is called "breaking behavior" (Naumann 1975).

Increasing numbers of wasps drag on vegetation along the route to the new nest and are gradually replaced by increasing numbers of follower wasps until numerous wasps are flying along the entire

*Manuscript received by the editor Feburary 4, 1980. 
route. After followers appear, the number of wasps at the swarm site dwindles rapidly, but there is continuous activity there as wasps fly in and out of the swarm. Movement of the swarm is completed in less than one hour. Since Naumann (1975) found similar behavior by species in four genera, Angiopolybia, Leipomeles, Polybia and Stelopolybia, it may be typical of all or most polybiines.

We have observed such behavior on several occasions in Angiopolybia pallens (Lepeletier) and Polybia catillifex Moebius when colonies moved after they were attacked by army ants. However, the behavior of the wasps was distinctly different following a raid by Eciton rapax Fr. Smith on a nest of Polybia velutina Ducke (colony V-535, Ecuador). The nest in a large Codeum bush was raided on 24-VI-1977 at 5:30 PM, and the wasps started a swarm on several leaves on the north side of the same bush 15-20 min after leaving the nest. The swarm consolidated on 2 leaves about $1.3 \mathrm{~m}$ north of the nest during the next 2 hours. Based on photographs of the swarm taken about 11:45 PM, there were 325-375 wasps in the colony.

At 1:40 PM the next day, 20 hours after the wasps absconded and more than 2 hours before the swarm moved, we located the new nest site on a wire under a nearby house. There were 17 wasps at the new location which was $8 \mathrm{~m}$ south of the swarm. Earlier in the day wasps were observed flying north and south from the swarm, but the northern flights were abandoned shortly after 1:00 PM. Despite the short distance between the swarm and the new nest, it was impossible for the wasps flying from the swarm at a height of $2.3 \mathrm{~m}$ to see the new site at a height of $1.8 \mathrm{~m}$ because it was hidden by the thick Codeum bush and an overhang on the side of the house. The new nest site would not be within sight of the wasps until they approached it at a height of about $1.5 \mathrm{~m}$ in the last $2 \mathrm{~m}$.

The wasps did not fly directly to the new nest site but flew around the east or west sides of the Codeum shrub, a total flight distance of 9-10 m. Between the swarm and the new nest site there were approximately $3 \mathrm{~m}$ of Codeum foliage and 3 posts $1-2 \mathrm{~m}$ high. To see if we could stimulate dragging behavior, we placed a wooden chair in the flight path of the wasps at 2:36 PM in the area of about $3 \mathrm{~m}$ where there was no vegetation higher than a few centimeters and no posts. The wasps ignored this potential substrate for chemical marking.

At the swarm there was a high level of activity. A typical count at 2:22 PM showed 11 wasps arriving and 9 leaving per minute. Wasps were seen landing on the swarm and performing breaking behavior. 
For example, a wasp with its wings raised at a $45^{\circ}$ angle excitedly ran over the bodies of the wasps to the top of the leaf, turned and ran half the length of the leaf touching many wasps and again ran up through the center of the swarm before stopping to groom.

For more than $2 \mathrm{hr}$ the number of wasps on the wire at the new nest site fluctuated from 7-25 (Table 1). Most were constantly palpating $35 \mathrm{~cm}$ of the wire with their antennae and mouthparts as they slowly walked back and forth over it. The activity was suggestive of cleaning since the wasps nibbled almost imperceptibly at the wire with mandibles that were barely open and moved their maxillae actively. No wasp was ever observed dragging its gaster on the wire.

Table 1. Timing of swarm movement of Polybia velutina on 25 June 1977.

\begin{tabular}{|c|c|c|c|}
\hline $\begin{array}{c}\text { Time } \\
P M\end{array}$ & Swarm Site & $\begin{array}{c}\text { Numbers of Wasps } \\
\text { in Flight }\end{array}$ & New Nest Site \\
\hline $1: 40$ & $300^{\mathrm{a}}$ & - & 17 \\
\hline 2:00 & $300^{\mathrm{a}}$ & - & 25 \\
\hline $2: 15$ & $300^{\mathrm{a}}$ & - & 9 \\
\hline $2: 20$ & $300^{\mathrm{a}}$ & - & 13 \\
\hline $2: 35$ & $300^{\mathrm{a}}$ & - & 7 \\
\hline $2: 40$ & $300^{\mathrm{a}}$ & - & 15 \\
\hline $2: 55$ & $300^{a}$ & - & $18-22$ \\
\hline $3: 40$ & $300^{\mathrm{a}}$ & - & $20-26$ \\
\hline $4: 10$ & $200^{\mathrm{a}}$ & $25-30$ & $50^{\mathrm{a}}$ \\
\hline $4: 15$ & 20 & $40-50$ & $200^{\mathrm{a}}$ \\
\hline $4: 23$ & 10 & $5-10^{a}$ & $200^{\mathrm{a}}$ \\
\hline $4: 30$ & 10 & $5-10^{a}$ & $200^{\mathrm{a}}$ \\
\hline $4: 40$ & 8 & $5-10^{a}$ & $200^{2}$ \\
\hline $4: 50$ & 11 & $5-10^{a}$ & $200^{\mathrm{a}}$ \\
\hline $5: 40$ & 1 & - & $200^{\mathrm{a}}$ \\
\hline $6: 00$ & 0 & - & $200^{\mathrm{a}}$ \\
\hline
\end{tabular}

aestimated

The number of wasps at the new nest site increased rapidly between 3:40 and 4:00 PM, indicating the beginning of the major emigration. At that time 25-30 wasps were also simultaneously in flight between the 2 sites. The first carton was added to the wire between 4:00 and 4:10 PM, and the number of wasps in flight increased to 40-50. The wasps hovered in the air making a diffuse cloud of wasps along the path between the swarm and the new nest. Several wasps landed briefly on leaves of the Codeum, and 2 wasps dragged their gaster, each on different leaves. On a third leaf, 3 wasps paused in what 
appeared to be a dragger-follower-dragger sequence. With those exceptions no dragging or following behavior was observed during the afternoon while both of us were constantly present. By 4:15 PM the majority of wasps were at the new nest site, though until 5:40 PM a few wasps were constantly at the old swarm site.

There was no convincing evidence that the wasps used a trail of chemical spots to orient to the new site or that the nest site itself was chemically marked by Richards' gland. The limited dragging on 3 prominent leaves resulted in no systematic follower visits, with the exception noted above. Since polybiines are able to learn the location of food even a hundred meters away from the nest (Forsyth 1978), foragers active before the raid must have been familiar with landmarks within $10 \mathrm{~m}$ of their old nest. It, therefore, seems probable that many wasps could have learned the short route to the new nest site during the $2 \mathrm{hr}$ before the emigration. The hovering wasps along the path to the new nest site at the peak of the emigration could have guided any naive wasps. It is also possible that pheromone from Richards' gland or some other source provided an aerial plume for orientation, although we saw no evidence of this in the behavior or posture of the wasps. Unfortunately, we did not record the wind direction at the time, but the prevailing winds are from the east to northeast or at a right angle to the flight path.

Another swarm, Protopolybia exigua binominata (Schulz) (colony V-346, Panama), also appeared to move to a new nest site without the use of a pheromonal trail. Immediately after the wasps were experimentally evicted from their nest (by placing a few army ants near the nest), several wasps dragged their gasters along the edges of leaves close to the abandoned nest. The tip of the gaster did not touch the substrate, but the distal sternites contacted the leaf as in typical dragging behavior. By 5:30 PM, $3 \mathrm{hr}$ after the wasps had been ousted from their nest, the swarm of about 200 had consolidated on a nearby leaf, and the wasps were flying from the swarm into the distance. The next day at 9:35 AM there were many wasps landing on various leaves near the swarm. No dragging or following behavior was observed; the wasps merely landed momentarily on leaves. The new nest was located on the underside of a leaf only 2-3 m from the swarm leaf and about $1 \mathrm{~m}$ higher. There were many intervening leaves between the 2 sites, and the wasps did not follow any one path through the vegetation to get to or from the new nest site. By 9:45 AM the old swarm site 
had been abandoned and only an occasional wasp appeared there afterward. Several wasps at the new nest site were observed dragging their gasters on the edge of the new nest leaf after 10:00 AM.

In only 10 min most of the wasps flew to the new site, less than $3 \mathrm{~m}$ from the swarm. The short distance and the large number of wasps enhanced the probability that the wasps were following other individuals visually or by an aerial pheromone trail. No systematic visits, marking, or antennation at specific sites were observed. Forsyth (1978) noted that visual cues may be important or used in conjunction with a pheromone trail during short movements of Polybia occidentalis (Olivier).

The shortest distance for a swarm emigration observed by Jeanne (1975) was $70 \mathrm{~m}$ and Naumann (1975) reported distances of 3-33 m. Perhaps a continuum of behavior exists; for short distances the wasps rely on learning and visual cues for orientation and as the emigration distance increases they rely increasingly on chemical-spot trails. Honey bees also shift their orientation-communication system as the distance to food increases (Frisch 1967:57).

Although Jeanne's (1980) recent research supports that secretions from Richards' gland deposited during dragging behavior form a scent trail, such behavior is not restricted to trail formation. The dragging at the new nest site by $P$. exigua well after the emigration was completed may have been an ill-timed part of the emigration process, or a method of reinforcing recognition of a new nest. Dragging behavior was also observed in a context other than swarm emigration in Polybia scrobalis Richards.

When army ants were placed on or held near 2 nests of Polybia scrobalis (colonies V-377, V-443, Panama), 50-100\% of the adults flew. Wasps started returning to the nest immediately, and 10-20\% of those returning dragged their gasters in the typical manner on the nest carton, nest leaf, adjacent leaves, and occasionally on their nestmates. This response could not be elicited by holding Paraponera clavata (F.) or Ectatomma tuberculatum (Olivier) next to the wasps' nest, but on one occasion when a worker of Camponotus sericeiventris (Guerin) was held up to the nest a similar evacuation was accompanied by dragging both before and after flight. Such frequent dragging behavior by alarmed wasps and wasps which have left their nest for less than one minute was not observed during similar experiments performed with 30 species of polybiines in Panama and Ecua- 
dor (Chadab 1979). This suggests that in at least Polybia scrobalis gaster-dragging behavior or chemicals deposited as a result of that behavior, may have other functions than identifying the path to a new nest site.

\section{ACKNOWLEDGMENTS}

We thank O. W. Richards for identifying the wasps, R. L. Jeanne, C. S. Henry, and B. Hölldobler for criticizing the manuscript, The Smithsonian Tropical Research Institute (STRI) for providing facilities on Barro Colorado Island, Panama, and the Summer Institute of Linguistics for providing facilities at Limoncocha, Ecuador. Ruth Chadab was funded by a Visiting Research Appointment from STRI and a National Science Foundation Doctoral Dissertation Improvement Grant; Carl W. Rettenmeyer was funded by NSF Grant BMS 75-03389.

\section{Literature Cited}

Chadab, R.

1979. Army-ant predation on social wasps. Unpublished Ph.D. Thesis. Univ. of Connecticut. $260 \mathrm{p}$.

FORSYTH, A. B.

1978. Studies on the behavioral ecology of polygynous social wasps. Unpublished Ph.D. Thesis. Harvard Univ. 226 p.

FRISCH, K. V.

1967. The dance language and orientation of bees, Belknap. Harvard Univ. Press, Cambridge, xiv +566 p.

JEANNE, R. L.

1975. Behavior during swarm movement in Stelopolybia areata. (Hym.: Vespidae). Psyche 82: 259-264.

1980. Evolution of social behavior in the Vespidae. Ann. Rev. Entomol. 25: 371-396.

NaumanN, M. G.

1975. Swarming behavior: Evidence for communication in social wasps. Science 189: 642-644. 

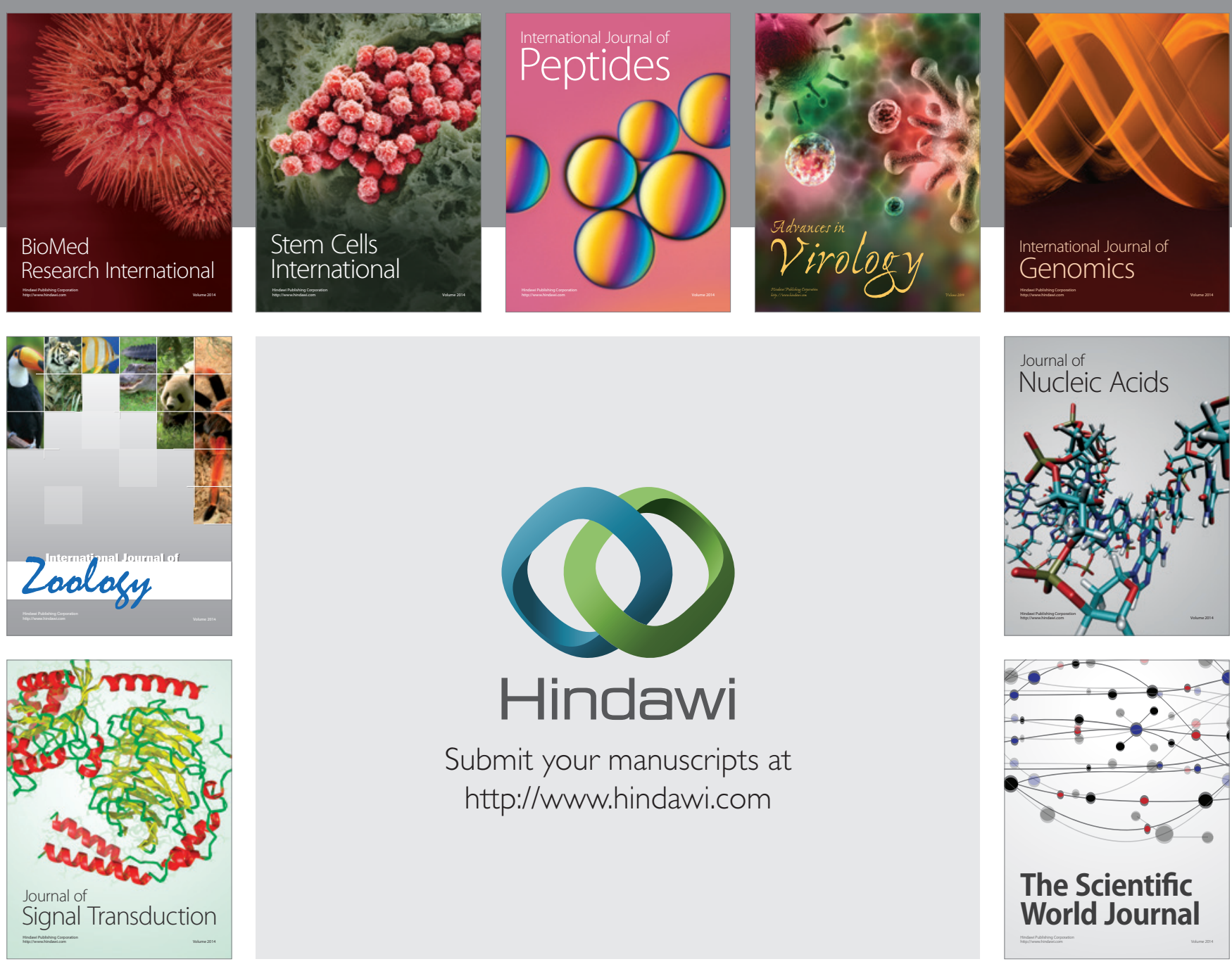

Submit your manuscripts at

http://www.hindawi.com
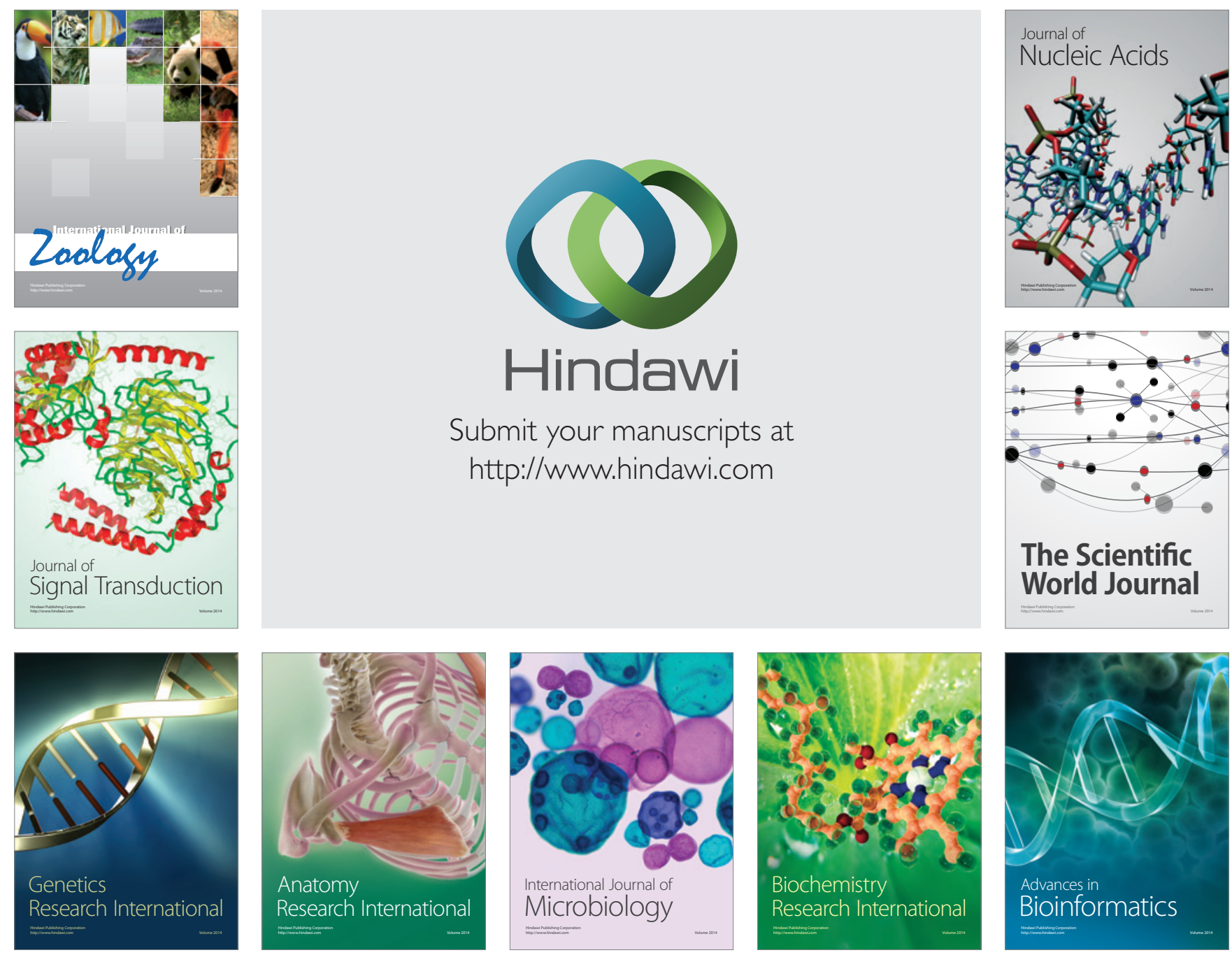

The Scientific World Journal
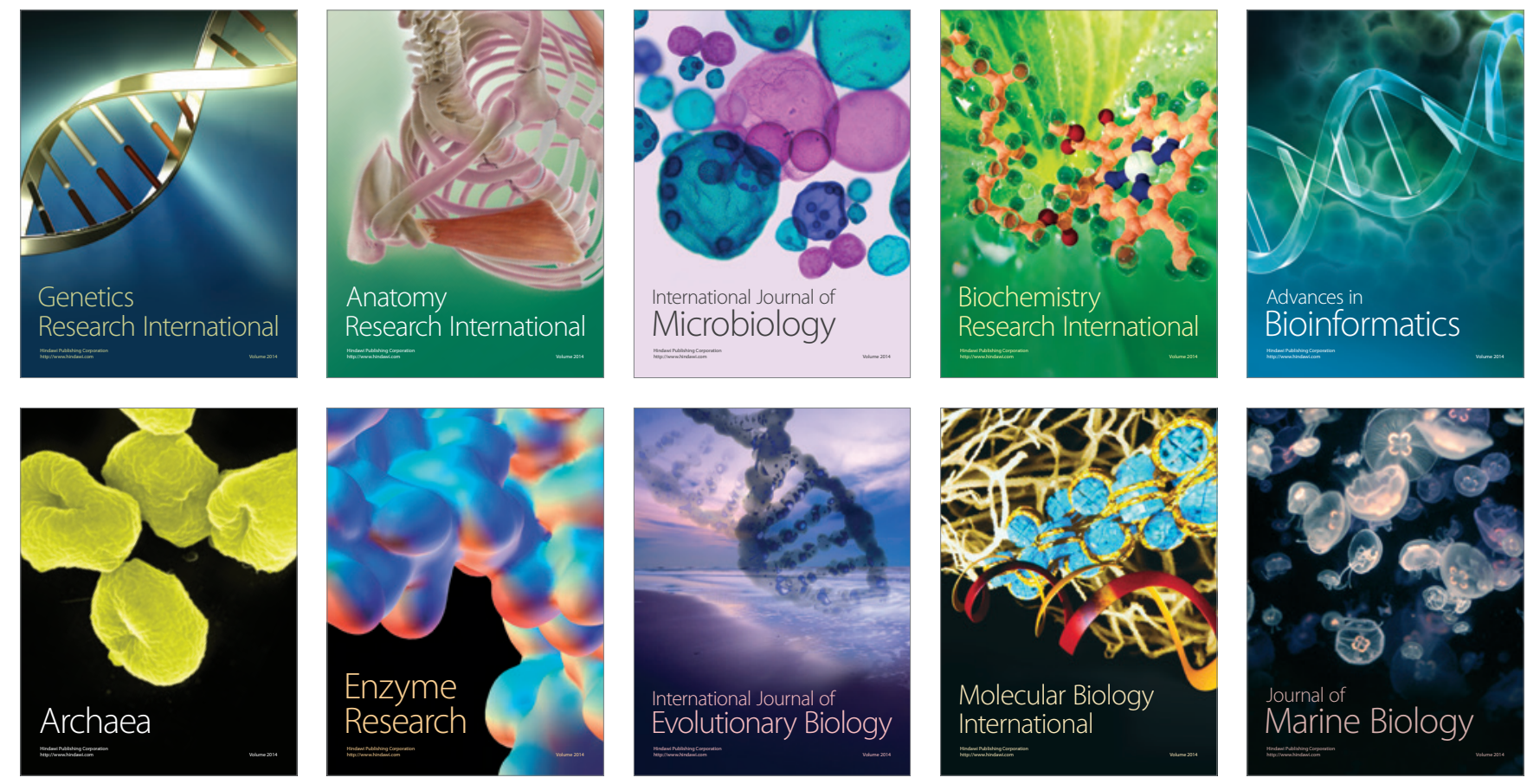